\title{
Ovulation Leads Women to Perceive Sexy Cads as Good Dads
}

\author{
Kristina M. Durante \\ The University of Texas at San Antonio
}

\author{
Vladas Griskevicius, Jeffry A. Simpson, and \\ Stephanie M. Cantú \\ University of Minnesota, Twin Cities Campus
}

\begin{abstract}
Why do some women pursue relationships with men who are attractive, dominant, and charming but who do not want to be in relationships - the prototypical sexy cad? Previous research shows that women have an increased desire for such men when they are ovulating, but it is unclear why ovulating women would think it is wise to pursue men who may be unfaithful and could desert them. Using both college-age and community-based samples, in 3 studies we show that ovulating women perceive charismatic and physically attractive men, but not reliable and nice men, as more committed partners and more devoted future fathers. Ovulating women perceive that sexy cads would be good fathers to their own children but not to the children of other women. This ovulatory-induced perceptual shift is driven by women who experienced early onset of puberty. Taken together, the current research identifies a novel proximate reason why ovulating women pursue relationships with sexy cads, complementing existing research that identifies the ultimate, evolutionary reasons for this behavior.
\end{abstract}

Keywords: evolutionary psychology, ovulation, mating, mate selection, fertility

In 1939, when asked to comment on the prospects of his opponent the New York Giants, Brooklyn Dodgers manager Leo Durocher responded with "nice guys finish last" (Durocher \& Linn, 1975). This aphorism is often used to describe young men's success at dating, with many women saying they want a nice guy but nevertheless dating men who are not-so-nice (McDaniel, 2005). Across cultures, many women believe that a good romantic partner is someone who is reliable, is dependable, and will make a good father (Buss, 1991; Buss et al., 1990). Yet, many women pursue and are heartbroken by men who are charismatic, adventurous, physically attractive, and hopelessly unreliable (Buss, 2003; Kruger, Fisher, \& Jobling, 2003; Rhodes, Simmons, \& Peters, 2005). Indeed, whereas popular dating guides for men teach

Editor's Note. Julie Fitness served as the action editor for this article.JAS

This article was published Online First May 14, 2012.

Kristina M. Durante, Department of Marketing, College of Business, The University of Texas at San Antonio; Vladas Griskevicius, Carlson School of Management, University of Minnesota, Twin Cities Campus; Jeffry A. Simpson and Stephanie M. Cantú, Department of Psychology, University of Minnesota, Twin Cities Campus; Norman P. Li, School of Social Sciences, Singapore Management University, Singapore.

We are grateful to Noah Belson for assistance with writing the "cad" and "dad" scripts. We thank Carin Perilloux, Sarah Hill, and Sarah Feingold for their helpful contributions to this project.

Correspondence concerning this article should be addressed to Kristina M. Durante, College of Business, One UTSA Circle, The University of Texas at San Antonio, San Antonio, TX 78249. E-mail: kristina.durante@ utsa.edu bachelors how to be the "bad boy" women cannot resist (Louis \& Copeland, 2007), dating guides for women implore them to steer clear of commitment-phobic men and instead choose the reliable "Mr. Good Enough" (Gottlieb, 2010). Why is it that, despite continuous warnings and recurring heartbreak, many women keep pursuing the wrong guy?

In this article, we build on past research showing that women's desire for sexy, dominant, and charismatic men is related to their monthly ovulatory cycle (Gangestad, Simpson, Cousins, GarverApgar, \& Christensen, 2004; Thornhill \& Gangestad, 2008). Although previous work has shown that women experience an increased attraction to such men when they are ovulating, it is unclear why ovulating women would think it is wise to pursue relationships with men who may be unfaithful and might desert them. In the current research, we examine a potential proximate psychological mechanism that may motivate women to believe it is a good idea to pursue men who are sexy, dominant, and charismatic, but who are also likely to be unreliable partners-the prototypical "sexy cad." We propose that ovulation might lead women to perceive that sexy cads will become devoted parents. To test this idea, we investigate how ovulation influences women's perceptions of men. We show that hormonal changes associated with fertility produce specific perceptual shifts, strategically changing women's perceptions of some traits (but not others) in some men (but not others). Across three experiments, we demonstrate how, when, and why ovulation can lead Mr. Wrong to appear like Mr. Right.

\section{Sexy Cads Versus Good Dads}

Research indicates that men diverge in their mating strategies (Buss \& Schmitt, 1993; Gangestad \& Simpson, 2000). Some men 
adopt a short-term mating strategy associated with having multiple, less committed sexual partners. Other men adopt a long-term mating strategy associated with having fewer, more committed relationship partners. Although men may, at times, adopt a combination of these two strategies (see Lancaster \& Kaplan, 1992), most men generally pursue either a short-term or a long-term mating strategy (Draper \& Belsky, 1990; Draper \& Harpending, 1982).

Men who adopt different mating strategies also have different traits. Men adopting a short-term strategy tend to be more physically attractive and sexy (Gangestad \& Thornhill, 1997; Thornhill \& Gangestad, 1994), be more socially dominant and rebellious (Jobling, 2002; Kruger et al., 2003), engage in flashy and conspicuously show-off behavior (Griskevicius, Cialdini, \& Kenrick, 2006; Griskevicius et al., 2007; Sundie et al., 2011), and possess an exploitative social nature (Jonason, Li, Webster, \& Schmitt, 2009; Jonason \& Tost, 2010). These "sexy cads" not only adopt a "love them-and-leave them" attitude toward mating, but they also possess traits associated with Machiavellianism, subclinical psychopathy, and subclinical narcissism (Jonason et al., 2009; Jonason \& Webster, 2010; Paulhus \& Williams, 2002). As a result, men who pursue a short-term mating strategy tend to display lower levels of stability, agreeableness, warmth, and faithfulness (Campbell, Foster, \& Finkel, 2002; Paulhus, 2001; Paulhus \& Williams, 2002). In contrast, men who adopt a long-term mating strategy have the opposite set of features. Such men tend to be less physically attractive, less charismatic, and less dominant, but they are also more stable, agreeable, warm, and faithful (Gangestad, GarverApgar, Simpson, \& Cousins, 2007; Lancaster \& Kaplan, 1992). Because these traits are associated with being a good long-term partner and an investing father (see Simpson \& Gangestad, 1992), such men are referred to as "good dads" (Buss \& Schmitt, 1993; Li \& Kenrick, 2006; Schmitt, 2005).

Women, of course, ideally want the best parts of both types of men in a romantic partner (Buss \& Shackelford, 2008; Fletcher, Simpson, Thomas, \& Giles, 1999). Thus, many women seek sexy husbands - men who are attractive, charismatic, and dominant, while also being faithful, reliable, and investing fathers (Li, Bailey, Kenrick, \& Linsenmeier, 2002). However, because it is difficult to find and secure such an ideal mate, most women must make a trade-off between pursuing long-term relationships with men who are good dads versus short-term relationships with men who are sexy cads (Gangestad et al., 2007; Gangestad \& Simpson, 2000; Li et al., 2002).

\section{Women's Ovulatory Cycle and Preferences for Sexy Cads}

Women are especially attracted to sexy, charismatic, and dominant men at a particular time each month. Many studies have documented that women's mating preferences are influenced by the hormonal fluctuations associated with their monthly ovulatory cycle (Gangestad \& Thornhill, 1998; Gangestad, Thornhill, \& Garver, 2002; Haselton \& Gangestad, 2006; Johnston, Hagel, Franklin, Fink, \& Grammer, 2001; Little, Jones, \& DeBruine, 2008; Lukaszewski \& Roney, 2009; Penton-Voak et al., 1999; Thornhill \& Gangestad, 2008; for reviews of this literature, see DeBruine et al., 2010; Gangestad \& Thornhill, 2008; Jones et al., 2008). During the few days each month when women are fertile, they tend to be more attracted to men who have more symmetrical and masculine faces (Gangestad, Thornhill, \& Garver-Apgar, 2010; Johnston et al., 2001; Penton-Voak \& Perrett, 2000; PentonVoak et al., 1999; Thornhill \& Gangestad, 2003; Thornhill et al., 2003), are more socially dominant and competitive (Gangestad et al., 2007, 2004), and have deeper voices (Feinberg et al., 2006; Puts, 2005). As discussed earlier, men who possess these traits typically adopt a short-term mating strategy, have more sexual partners, and exhibit exploitative personality traits (Frederick \& Haselton, 2007; Hughes \& Gallup, 2003; Jonason et al., 2009; Jonason \& Webster, 2010; Thornhill \& Gangestad, 1994). Near ovulation, therefore, women are more attracted to men who are prototypical sexy cads-charismatic, masculine, adventurous, physically attractive, but also unreliable long-term relationship partners (Buss, 2003; Gangestad et al., 2007).

Male characteristics such as greater symmetry, masculinity, and social dominance are purported to be markers of male genetic fitness (see Simpson, Gangestad, Christensen, \& Leck, 1999; Thornhill \& Gangestad, 2003, 2006). From an ultimate evolutionary perspective, ovulation is believed to lead women to desire men who have these features because such men can provide genetic benefits to potential offspring (Gangestad et al., 2004; GarverApgar, Gangestad, Thornhill, Miller, \& Olp, 2006; Penton-Voak et al., 1999; Pillsworth, Haselton, \& Buss, 2004). Supporting this evolutionary explanation, ovulating women show an increased desire for these types of men as sexual partners (Gangestad et al., 2002), particularly if a woman's current partner lacks genetic fitness indicators (Garver-Apgar et al., 2006; Pillsworth \& Haselton, 2006). Also consistent with the idea that sexy and dominant men can provide genetic benefits, there are no corresponding ovulatory shifts in desire for men who possess good dad traits, such as being faithful, kind, and warm (Gangestad et al., 2007).

\section{Proximate Reasons Why Ovulating Women Pursue Sexy Cads}

Biologists distinguish between two levels of explanation when examining animal behavior: ultimate explanations and proximate explanations (Kenrick, Griskevicius, Neuberg, \& Schaller, 2010; Mayr, 1988). Ultimate explanations concern the evolutionary function of behavior and consider the question of why a particular behavior has evolved to occur. Proximate explanations concern the immediate causes of behavior and consider the more mechanistic question of how a behavior occurs. These two levels of analysis are complementary and not competing, meaning that both are necessary for a complete understanding of behavior (Confer et al., 2010).

Much theory and research has converged on the ultimate evolutionary reason why ovulating women pursue sexy cads: Ovulating women seek such men because doing so can provide genetic benefits to offspring (Gangestad \& Thornhill, 1998; Penton-Voak et al., 1999; for a review, see Thornhill \& Gangestad, 2008). In the current research, we do not contest or test this widely supported ultimate reason for why ovulating women pursue men who are symmetrical, sexy, and socially dominant.

Instead, the current research considers proximate reasons for this effect. We examine the proximate psychological mechanism that causes ovulating women to seek symmetrical, sexy, and socially dominant men. Past research has proposed that the proxi- 
mate reason why ovulating women seek symmetrical, sexy, and socially dominant men is because women have increased desire to have short-term sexual relations with such men when ovulating (Gangestad et al., 2004; Penton-Voak et al., 1999). We do not contest or re-test this proximate mechanism, which has been welldocumented in multiple studies (Gangestad, Thornhill, \& GarverApgar, 2005; Haselton \& Gangestad, 2006; Pillsworth et al., 2004). Instead, we propose another, very different proximate mechanism that might also contribute to the effect. That is, although the benefits of pursuing short-term sexual relationships with a genetically fit man should sometimes outweigh the potential costs of doing so (Gangestad \& Simpson, 2000), it is unclear how women, who tend to be more oriented to long-term mating and less likely to pursue casual sexual opportunities (Buss \& Schmitt, 1993; Clark \& Hatfield, 1989), come to believe it is wise to have sex and pursue relationships with men who are more likely to cheat on, lie to, and eventually leave them (Gangestad \& Thornhill, 1997; Møller \& Thornhill, 1998; Waynforth, 2001).

We propose that another proximate reason why ovulating women are attracted to symmetrical, sexy, and socially dominant men is because women might perceive such men as better fathers and more committed partners when the women are ovulating. Near ovulation, in other words, women might view such men as different people. We propose that ovulating women might experience a shift in perception, perceiving that sexy cads will be devoted parents and partners. The belief that a sexy cad would make a high-investing long-term partner could serve an important proximate function by reducing the perceived costs associated with mating with such men. Given the evolutionary benefits of mating with genetically fit males, seeing a sexy cad as good relationship material might provide ovulating women with the extra "push" needed to take the risk and have sex with sexy cads and, thus, extract genetic benefits from them. Accordingly, in three studies we tested whether ovulating women tend to view sexy cads as potential partners who are particularly likely to be investing fathers. To do this, we measured women's perceptions of men's willingness to contribute to offspring care.

\section{Study 1: Ovulation and Perceptions of a Sexy Versus a Reliable Man}

Study 1 tested whether ovulation leads women to perceive sexy cads as investing dads. We predicted that ovulation would lead women to perceive sexy, adventurous, and charismatic men-but not reliable, stable, and dependable men-as more-investing future fathers.

\section{Method}

Participants. Participants were 33 female undergraduate students (mean age $=18.46$ years). Women participated in exchange for extra-credit in psychology courses or for a $\$ 30$ cash payment.

\section{Procedure.}

Assessing fertility. Following procedures recommended by Durante, Li, and Haselton (2008), we prescreened women over the telephone. Only women who reported having regular monthly menstrual cycles (i.e., cycles running 25-35 days in length) and who reported having none of the following issues were included in the study: current or recent use of hormonal contraceptives (i.e., use of hormonal contraceptives within the past 3 months), recent birth of a child and/or currently breastfeeding a child, experience of dramatic changes in weight, use of antidepressants, or regular cigarette smoking.

Based on the cycle information provided during the telephone interview, each participant visited the lab twice: once on a highfertility day (near ovulation) and once on a low-fertility day. Whether a woman was scheduled for high- or low-fertility testing depended on where she was at in her current menstrual cycle when she completed the phone interview. Prior to the high-fertility session, women came to the lab to complete luteinizing hormone (LH) tests (i.e., unmarked over-the-counter urine applicator testsClearblue Easy Ovulation Test Kit) to pinpoint their day of ovulation. The first urine test was scheduled 2-3 days before the expected day of ovulation. If an LH surge was not detected, women came back each day until an LH surge was detected. If any of the days required to detect ovulation fell on a weekend, the participant was given testing sticks and directions to take the test at home and to return it to the lab on Monday.

As a cover story for the urine tests, women were told that the study was investigating how certain health variables are associated with typical mate preferences. Women were informed that they needed to complete the urine tests so we would have a better assessment of their health, consistent with the cover story. They were also assured that the urine tests could not be used to test for pregnancy, drug use, or disease, and they would be told what the urine tests measured at the debriefing session. On average, highfertility testing sessions took place 0.72 days after the $\mathrm{LH}$ surge or 0.28 days before the day of ovulation; low-fertility testing sessions occurred 4.43 days before menses.

After the study was completed, detailed debriefing sessions indicated that none of the participants were aware of the research hypothesis (i.e., that we were investigating changes in women's perceptions of men at different points in the menstrual cycle), and none knew that the urine tests were being used to detect ovulation.

Photos and profiles. Women were randomly assigned to either a sexy man or a reliable man experimental condition. In the sexy man condition, women viewed a photo of a physically attractive man along with a brief biographical profile describing him as socially dominant, adventurous, and charismatic. The profile also described him as a skier who has won several awards and as someone who loves the outdoors. In the reliable man condition, women viewed a photo of an average-looking man along with a brief biographical profile describing him as stable, a good provider, and dependable. The profile also described him as a successful accountant who works hard and has won several promotions. Participants viewed the same photo-profile at both high- and low-fertility sessions.

We used photos of pre-rated facial pictures of two highly attractive men for the sexy man condition $(M=7.24$; 9-point scale) and two average-looking men for the reliable man condition $(M=3.68)$. Pre-ratings of each of the men by a different sample of 38 female undergraduate students indicated that the sexy man profile was perceived as more socially dominant, adventurous, and charismatic $(\alpha=.81)(M=7.70, S D=0.91)$ than the reliable man profile $(M=4.72, S D=1.28), t(37)=11.71, p<.001$. Conversely, the reliable man profile was perceived as more stable, dependable, and reliable $(\alpha=.86)(M=7.32, S D=1.37)$ than the sexy man profile $(M=5.34, S D=1.14), t(37)=-6.12, p<.001$. 
Dependent measures. Participants were asked to imagine meeting the man in each profile. They then indicated the expected paternal contribution from the man in potential offspring if they had a child with him. Specifically, participants reported each man's contribution to (a) caring for the baby (e.g., feeding, giving the baby a bath), (b) shopping for food and cooking, and (c) contributing to general household chores (e.g., assembling baby furniture, washing bottles). For each item, participants indicated the percentage of time and effort (out of 100\%) they expected the man would contribute to each childcare domain. Participants were told to split $100 \%$ (i.e., assuming the woman's contribution would be the remaining percentage out of $100 \%)$. These three items formed the expected paternal investment composite $(\alpha=.86)$.

\section{Results and Discussion}

An analysis of variance (ANOVA) with Fertility (high vs. low) as a within-subjects factor and Target Male (sexy vs. reliable) as a between-subjects factor revealed a significant interaction, $F(1$, 29) $=5.10, p=.032$ (see Figure 1). As predicted, women expected that the sexy man would invest relatively more in their potential offspring when they were near ovulation compared to when they were not ovulating, $F(1,15)=4.43, p=.053, \eta^{2}=$ .23. However, ovulation did not influence perceptions of the reliable man $(p=.39)$. In other words, ovulation led sexy and adventurous men to be perceived as better future fathers, but it did not influence the perceptions of men who were stable and dependable. These findings provide a proximate psychological reason why ovulating women might accept advances from sexy cadsovulation induces women to believe that such men may, in fact, be more investing fathers.

One limitation to Study 1 is that ovulating women did not perceive that the reliable man would contribute more to offspring care than the sexy cad. This may be because the women evaluated only one type of man (reliable or cad) at each testing session. In Study 2, we resolved this limitation.

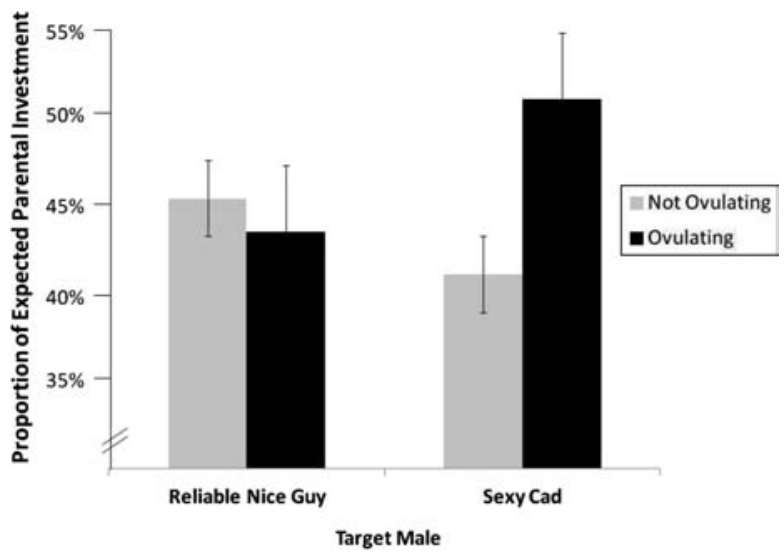

Figure 1. Women's expected parental investment in a child (out of $100 \%$ ) by a charismatic cad versus a reliable nice guy (dad) as a function of whether the woman is ovulating (Study 1). Error bars indicate the standard error of the mean.

\section{Study 2: Investing in My Children Versus Another Woman's Children}

Study 2 was designed to conceptually replicate and extend the finding of Study 1. In Study 2, women at high versus low fertility interacted via a videocamera system with men (actually professional actors) who assumed the role of a sexy cad or a reliable dad. To control for features across the two types of men (e.g., facial symmetry, perceived health, etc.), the same male actors portrayed both types of men (see the Method section). Immediately after interacting with each of the two men, women indicated how much paternal investment each man would contribute to potential offspring.

We also tested the specificity of the ovulatory perceptual shift effect found in Study 1. Study 1 found that ovulation leads women to over-perceive that sexy cads are likely to become good dadsthat an adventurous charmer will transform into an investing and devoted father. Because the reproductive benefits of mating with a sexy cad near ovulation are specific only to oneself (i.e., only the woman mating with the sexy cad can get genetic benefits), ovulatory-induced over-perception of paternal investment should be strongest when evaluating the sexy cad for oneself rather than for another woman. Indeed, previous research examining positive illusions in romantic relationships has found that biases in partner perceptions emerge with respect to how positively individuals view their partners relative to how other people view their partners (Murray, Holmes, Dolderman, \& Griffin, 2000; Murray, Holmes, \& Griffin, 1996a, 1996b). For example, when asked to evaluate their romantic partners, individuals attribute more virtues (e.g., artistic/musically skilled, physically attractive, athletic, socially skilled, and intelligent) to their partners than their partners' close friends do. Moreover, individuals also perceive their romantic partners as more virtuous than the partners even perceive themselves to be (Murray et al., 2000).

Because women should not perceive sexy cads to be better dads when evaluating these men as the partners of other women, we predicted that ovulating women would perceive sexy cads as being better fathers for their own offspring, but not for the offspring of other women. The ovulatory perceptual shift effect, therefore, should be confined to each woman and her relationship with the cad, facilitating her interest (but not the interests of another woman) in him as a potential mate. Thus, we asked women how much investment each type of man would contribute to offspring if she was his romantic partner versus if another woman was his romantic partner. We predicted that ovulating women would perceive that sexy cads would invest more in their own children, but would not necessarily invest more in the children of another woman.

Finally, to examine the possibility that the findings might be driven by a fertility-induced halo effect for sexy cads, we also assessed perceptions of each man's attractiveness, financial status, and social status.

\section{Method}

Participants. Participants were 21 female undergraduate students (mean age $=20.29$ years). All women were normally ovulating, and none were taking any form of hormonal contraception. 
Women participated in exchange for extra-credit in psychology courses or for a $\$ 30$ cash payment.

\section{Procedure and materials.}

Assessing fertility. Women were recruited with fliers posted around campus and class advertisements to participate in a study on "twin communication, relationships, and health." Interested participants were told to e-mail or call the laboratory to learn more about the study. A trained research assistant then conducted a telephone pre-screening interview. The procedure for assessing fertility was identical to Study 1. As in Study 1, women were told that we were interested in how health variables were related to relationship preferences, and that the urine tests served as one indicator of current health, consistent with the cover story. On average, high-fertility testing sessions took place 0.71 days after the LH surge or 0.29 days before the day of ovulation; low-fertility testing sessions occurred 6.71 days before menses. Detailed debriefing indicated that none of the participants were aware of the research hypotheses, and none believed the urine tests were being used to detect ovulation.

Sexy cad and good dad. Participants were told the study investigated how identical twins communicate and interact with potential relationship partners. Participants were told that they would watch men (who ostensibly were identical twins) introduce themselves via a live video feed. Participants were led to believe that each man was in another nearby lab. The men, however, were videotaped professional actors.

Two male actors played both the roles of sexy cad and reliable dad. Each actor recorded two 2-min videos based on scripts developed by the experimenters (see the Appendix). In each video, each man first introduced himself to "a potential date." The role of the sexy cad involved acting socially dominant, charismatic, and adventurous, while also coming across as unreliable and undependable. The role of reliable dad involved being socially reserved, not being charismatic or adventurous, and explicitly desiring a committed relationship and a family. To control for features such as facial appearance, each actor played both the sexy cad and the reliable dad. When switching between roles, actors alternated outfits and grooming (e.g., changed clothes and hairstyles).

Pre-ratings by a different sample of 13 undergraduate women indicated that the men in the sexy cad videos were indeed perceived as more attractive, sexy, leader-like, and brave $(\alpha=.86)$ $(M=6.74, S D=0.76)$ than the men in the reliable dad videos $(M=5.31, S D=0.69), t(12)=6.25, p<.001$. Conversely, the men in the reliable dad videos were perceived as much more trustworthy, kind, nice, and reliable $(\alpha=.93)(M=7.24, S D=$ 1.46) than the men in the charismatic cad videos $(M=3.26, S D=$ $0.98), t(12)=9.53, p<.001$.

Each participant viewed four videos across two sessions (at both high and low fertility). For example, in the first session, a woman viewed an introduction by a sexy cad and a reliable dad played by different actors. Several days later in Session 2, she then viewed each man's "twin," watching the same actors from Session 1 playing the opposite roles. The order in which participants viewed the videos was randomized.

In line with the cover story, participants were told that the study examined "twin romantic preferences," so each twin had been instructed to introduce himself as a potential dating partner. Research assistants carefully read an instruction script to the participant at both of her sessions to ensure she understood the "pur- pose" of the study. The instructions explained that the participant would see two different people who each had a twin, and that she would see the individuals' twin at her second session. This cover story was quite believable because twin research is regularly conducted at the University of Minnesota, where this study was conducted.

Research assistants followed a prearranged protocol to behave as if the men were in a nearby room. For example, research assistants "tested" the cameras in different lab rooms and asked the women to work on another task because "we have to wait for the twin to arrive." When he apparently did, the research assistant walked into the room in which the man was purportedly waiting and read instructions aloud to create the perception that he was being led through the same consent process. The full procedure was then pilot tested with a series of female undergraduate students who were blind to the purpose of the research. Detailed debriefings after the pilot testing revealed that all of the women believed the men were "live" in the other room, and none suspected the process was contrived.

Manipulation checks for participants in Study 2 also indicated that none of the participants were aware of the research hypotheses, and all of them believed the men were real and in nearby lab rooms.

Dependent measures. Women reported each man's expected paternal investment by answering three questions on 9-point scales: "If you and the man had a baby ..." (1) "How much do you think he would invest in helping with childcare?"; (2) "How much do you think he would invest in helping with daily childcare chores like changing diapers and giving the baby baths?"; and (3) "How much do you think he would help prepare food for and feed the baby?" These three items formed the paternal-investment in one's own child composite $(\alpha=.91)$.

Women were also told that, "The man you just saw also introduced himself to another woman in the study. Imagine that the other woman and the interviewer had a baby." Women then answered the same three paternal investment questions re-worded to reflect a situation in which the man had a baby with the other woman. For example, "If the other woman and the interviewer had a baby, how much do you think the interviewer [man] would invest in helping with daily childcare chores like changing diapers and giving the baby baths?" These items formed the paternalinvestment in the other woman's child composite $(\alpha=.89)$.

Participants also reported their perceptions of each man's (1) attractiveness, (2) social status, and (3) financial status on 9-point scales.

\section{Results}

A repeated measures ANOVA with Fertility (high vs. low fertility), Target Male (sexy cad vs. reliable dad), and Target Partner (self vs. other woman) as within-subject factors revealed a significant three-way interaction, $F(1,19)=4.96, p=.038, \eta^{2}=$ .21 (see Figure 2). Although the two-way interaction between Fertility and Target Male did not reach significance, our specific predictions involved testing the significance of specific contrasts for perceptions of men by women who were or were not ovulating.

Replicating the main finding from Study 1, women perceived that sexy cads would invest more in paternal care when they were ovulating, $F(1,19)=6.50, p=.02, \eta^{2}=.26$ (see Figure 2 ). Also 

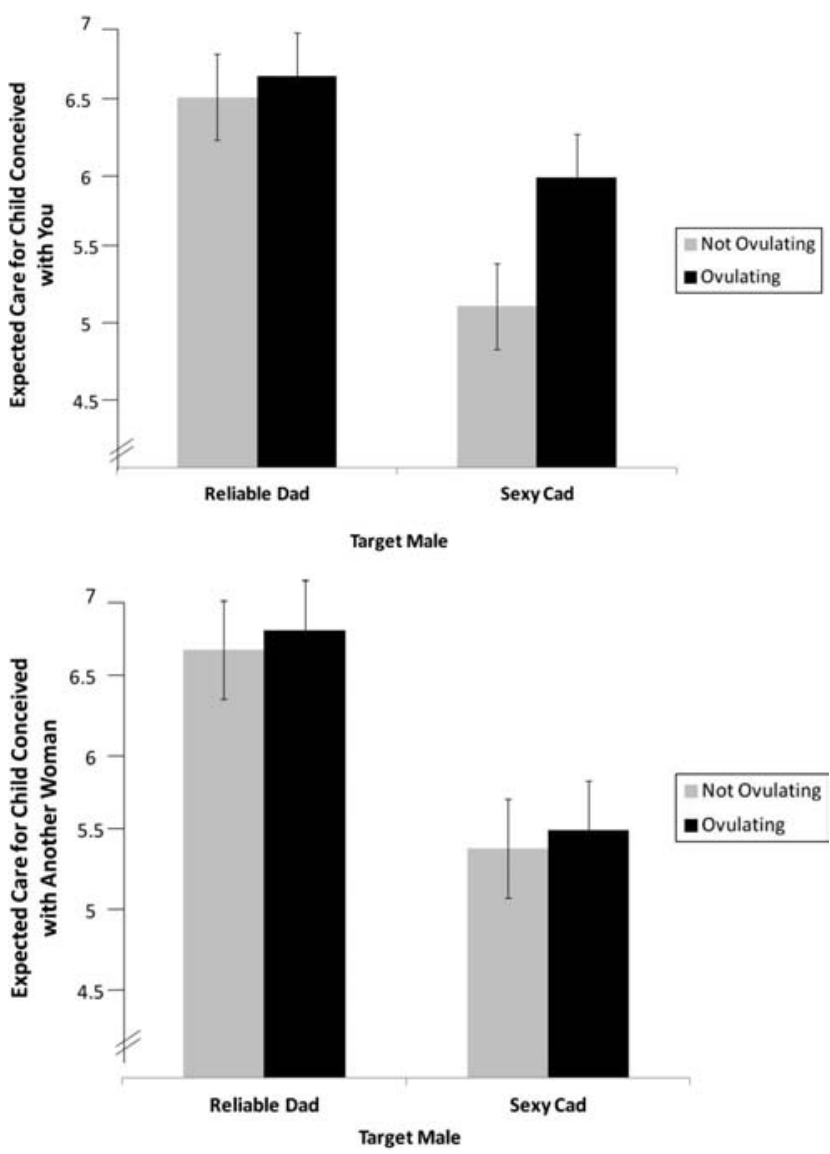

Figure 2. Women's expected paternal investment in a child by a sexy cad versus a reliable dad as a function of whether the woman is ovulating (Study 2). Top panel: Investment in woman's own child. Bottom panel: Investment in child of another woman. Error bars indicate the standard error of the mean.

replicating Study 1, there was no effect of fertility on expected paternal care from the reliable dad $(p=.71)$.

Although ovulating women perceived that sexy cads would invest greater paternal care in their own offspring, ovulating women did not perceive that sexy cads would invest more paternal care in the offspring with another woman ( $p=.68$; see Figure 2). Thus, ovulating women do not believe that sexy cads will make better fathers in general; they will be better fathers only if she is the mother.

Finally, there were no main effects of fertility or fertility by target male interactions for any of the other positive attributes: attractiveness, financial status, and social status (all $p s>.33$ ). Ovulation also had no effect on the perception of men's attractiveness $\left(M_{\text {low fertility dad }}=5.06, M_{\text {high fertility dad }}=4.73\right.$; $\left.M_{\text {low fertility cad }}=5.79, M_{\text {high fertility cad }}=5.65\right)$, financial status $\left(M_{\text {low fertility dad }}=4.76, M_{\text {high fertility dad }}=4.77 ; M_{\text {low fertility cad }}=5.64\right.$, $\left.M_{\text {high fertility cad }}=5.64\right)$, or social status $\left(M_{\text {low fertility dad }}=4.82\right.$, $M_{\text {high fertility dad }}=4.74 ; M_{\text {low fertility cad }}=6.21, M_{\text {high fertility cad }}=6.07$ ). The ovulatory-induced perception of paternal investment, therefore, is not produced by a halo effect when women evaluate sexy cads at high fertility.

\section{Discussion}

Study 2 conceptually replicated the findings of Study 1 . Employing a rigorous within-subjects design, results showed that ovulating women over-perceived the amount of paternal investment the sexy cad would provide to their potential offspring. The findings of Study 2 also revealed that this ovulatory-induced over-perception was specific to the self. Ovulating women overperceived the amount of paternal investment the sexy cad would bestow to their children, but not to children he might have with another woman. This finding indicates that the ovulation-driven over-perception effect is not a general perceptual bias that occurs near ovulation when women are evaluating attractive and charismatic men. Rather, it appears to be a specific perceptual bias that occurs when ovulating women are evaluating these men as potential romantic partners for themselves. One potential limitation of Study 2 is that women always evaluated men with regard to themselves first and then with regard to other women second. Although future research needs to determine whether these findings hold when using a counterbalanced design, it is important to note that this self-specific effect was found only in ovulating women and only when they evaluated the sexy cad.

Study 2 also tested whether the ovulatory-induced overperception of paternal investment was a product of a broader ovulatory-induced halo effect that occurs when women evaluate attractive and charismatic men. The results showed that there was no ovulatory effect on women's perceptions of the sexy cad's attractiveness, financial status, or social status. Thus, ovulation appears to shift women's perceptions of a man's willingness to invest in her offspring specifically, but not his other positive traits.

\section{Study 3: Ovulatory Perceptual Shifts and Pubertal Timing}

The final study attempted to conceptually replicate and extend the ovulatory perceptual shift effect in a larger and more diverse sample of women. In addition to obtaining measures of women's perceptions of sexy cads' paternal contribution, women in Study 3 also indicated how committed and stable they thought a sexy cad would be in a relationship. Consistent with our earlier findings that ovulating women perceive sexy cads as more investing fathers, we predicted that ovulating women in Study 3 would also perceive such men as more committed and stable relationship partners. Finally, as discussed in greater detail below, Study 3 also examined a theoretically important individual difference variable so we could determine which women are most likely to show the ovulatory perceptual shift.

An examination of women's mating patterns reveals that certain women also adopt different mating strategies (Buss \& Schmitt, 1993; Gangestad \& Simpson, 2000). Similar to men's mating strategies, the mating strategies of women vary from a fast, shortterm strategy (e.g., opportunistically having many sexual partners) to a slow, long-term strategy (e.g., having fewer committed and more reliable romantic partners). From an evolutionary perspective, the primary benefit of following a faster reproductive strategy for women is extracting genetic benefits from a mate because following a faster strategy enables women to access men of higher genetic quality (Gangestad \& Simpson, 2000). Accordingly, women who follow faster strategies are not only more attracted to 
men who display markers of genetic fitness (Smith et al., 2009; Waynforth, Delwadia, \& Camm, 2005); they also have less to lose from an evolutionary perspective if such men are not interested in pursuing a long-term relationship with them. That is, because women who adopt a fast reproductive strategy are primarily seeking good genes via sexual relations with sexy cads and because fast-strategy women are not expecting to always secure commitment from such men, the potential cost (in evolutionary terms) of failing to secure commitment from such men may be relatively small. By comparison, women who follow a slow reproductive strategy are primarily seeking a stable, committed, and invested partner; for such women, the cost of incurring a sexy cad's instability and likelihood of desertion is greater because slowstrategy women are expecting to secure commitment from a longterm partner. Hence, we predicted that women who are pursuing a fast reproductive strategy would be more likely to show the ovulatory perceptual shift effect because they have more to gain and less to lose from an evolutionary perspective by pursuing sexy, charismatic cads.

We assessed women's reproductive strategies by measuring a biological marker of faster versus slower female reproductive strategies: age at menarche. Age at menarche (i.e., the age at which a girl experiences her first menstrual period) is the most wellestablished marker of individual differences in fast-slow strategies at the biological level (see Belsky, Steinberg, \& Draper, 1991; Chisholm, 1999; Ellis, 2004, 2005; Kim \& Smith, 1998; Kim, Smith, \& Palermiti, 1997; Udry, 1979). Consistent with following a faster, short-term mating strategy, girls who experience puberty earlier tend to have sex at an earlier age and have more sexual partners (Flannery, Rowe, \& Gulley, 1993; Furstenberg, BrooksGunn, \& Chase-Lansdale, 1989; Luster \& Mittelstaedt, 1993; Udry, 1979), and they also show a stronger preference for masculine men (Jones, Boothroyd, Feinberg, \& DeBruine, 2010). To the extent that women who adopt a faster reproductive strategy could have benefitted evolutionarily by seeking investment from genetically fit men at the expense of possible mate desertion, we predicted that ovulating women who experienced menarche at an earlier age would be more likely to show the ovulatory perceptual shift effect. For these women, the perceptual shift may be adaptive because it increases the likelihood that they will approach and accept offers from sexy cads.

In summary, Study 3 had three goals. First, we sought to conceptually replicate the ovulatory perceptual shift effect from the first two studies in a more diverse sample of women. To do so, we obtained data from a large sample of women across the United States who were at different points in their ovulatory cycles. Unlike the first two studies, this methodology enabled us to test how women's perception of sexy cads fluctuates across the entire cycle. Second, in addition to assessing perceptions of sexy cads' paternal contributions, women also indicated how committed and stable they thought a sexy cad would be in a relationship. We predicted that ovulating women would perceive such men as relatively more committed and stable relationship partners. Finally, we investigated how ovulation influences perceptions of sexy cads for women following faster versus slower reproductive strategies. We predicted that ovulating women following faster strategies - as indexed by earlier age at menarche-would be most likely to show the ovulatory perceptual shift effect. Because Stud- ies 1 and 2 found no ovulatory effect for evaluations of reliable dads, we examined perceptions of only sexy cads in Study 3.

\section{Method}

Participants. Primary data were obtained from 318 normally cycling women who were not taking any form of hormonal contraception or prescription medication (e.g., antidepressants, cholesterol lowering statins). The mean age of participants was 27.84 years $(S D=5.94)$, ranging from 18 to 39 years of age. Women participated in exchange for payment via a World Wide Web hosting site (mTurk).

Participants were from 45 of the 48 contiguous United States plus Washington D.C. They identified their race as White/ Caucasian $(n=223)$, Asian $(n=36)$, Black/African American $(n=30)$, Hispanic/Latino $(n=12)$, American Indian/Native American $(n=2)$, Native Hawaiian/Pacific Islander $(n=2)$, Mixed Racial Ethnicity $(n=7)$, and Other $(n=6)$. The relationship status of participants included women who were Single/Not Dating $(n=92)$, Single/Dating More Than One Partner $(n=10)$, Single/Dating Only One Partner $(n=62)$, Engaged $(n=12)$, Living With Partner $(n=36)$, Married $(n=99)$, and Other $(n=$ 7 ). Some of the participants had biological children $(n=104)$, and others had no biological children $(n=214)$. Annual income ranged from $\$ 15,000 /$ year or less $(n=43)$ to more than $\$ 150,000 /$ year $(n=20)$. Median income was $\$ 35,001-\$ 50,000 /$ year $(n=$ 52). There was no effect of racial ethnicity, relationship status, existing biological children, or socio-economic status for any of the dependent measures (all $p \mathrm{~s}>.33$ ).

Secondary data were obtained for 166 women who were on a cyclic oral contraceptive (i.e., the pill). Women on cyclic contraceptives experience a pseudo 28-day menstrual cycle, but they do not experience the normal fluctuation of hormones across the cycle and do not ovulate (see Fleischman, Navarette, \& Fessler, 2010). We collected data from these participants as a comparison group for descriptive purposes.

Procedure and materials.

Assessing fertility. To ascertain fertility, we obtained the following from participants: (1) the start date of their last menstrual period and their previous menstrual period, (2) the expected start date of their next menstrual period, and (3) the typical length of their menstrual cycle. We then used the reverse cycle day (RCD) method to predict the day of ovulation for each participant. The RCD method is a reliable measure of fertility status (see DeBruine, Jones, \& Perrett, 2005; Durante, Griskevicius, Hill, Perilloux, \& Li, 2011; Gangestad \& Thornhill, 1998; Haselton \& Gangestad, 2006). Based on these established methods, women across the cycle were divided into a high fertility group and a low fertility group.

The chances of becoming pregnant from one act of sexual intercourse increases substantially during the ovulatory phase of the cycle (see Wilcox, Dunson, Weinberg, Trussell, \& Baird, 2001). Following the conception probability curve, the high fertility group consisted of women who had a conception probability above 5\% (Cycle Days 9-17; $n=101$ ). The low fertility group consisted of women who had a lower conception probability on days following ovulation (Cycle Days $18-25 ; n=74$ ). For our main analyses, we did not include women at the beginning of the ovulatory cycle (Cycle Days 1-8) or at the very end of the 
ovulatory cycle (Cycle Days 26-28) to avoid potential confounds due to premenstrual, menstrual, or perimenstrual symptoms.

Cad profile. Each participant read the sexy man profile (without the accompanying photograph) from Study 1. This brief biographical profile described a socially dominant, adventurous, and charismatic man.

Dependent measures. Participants imagined meeting and getting to know the man in the profile. They then answered four questions about their perceptions of the man on a 9-point scale ranging from 1 (not at all) to 9 (extremely). Two questions centered on perceptions of the man's future Paternal Investment: (1) "If you and this man had a baby, how much do you think he would invest in helping with childcare?" and (2) "If you and this man had a baby, how much do you think he would invest in helping with daily childcare chores like changing diapers and giving the baby baths?"

The two other questions focused on perceptions of the man's future Commitment and Stability: (1) "If you and this man were in a romantic relationship, how committed do you think he would be to you?" and (2) "How stable and dependable would you say this man is?"

Age-at-menarche. To index fast versus slow reproductive strategies, we assessed women's age at the time of menarche (i.e., the first menstrual period). Age at the first menstrual period is a reliable marker of a woman's reproductive maturation and a life event that most women can report with considerable accuracy (see Ellis, 2004). Participants answered the following question: "How old were you when you had your first menstrual period?" The average age of menarche in the sample was 12.29 years $(S D=$ 1.45), ranging from 6 to 18 years.

\section{Results}

Paternal investment. We first examined how fertility and age-at-menarche influenced perceptions of paternal investment for normally cycling (non-pill using) women. A general linear model with Fertility (high vs. low) as a between-subjects factor and Age-at-Menarche as a zero-centered continuous factor revealed a significant interaction between fertility and age-at-menarche, $F(1$, $171)=10.59, p=.001, \eta_{p}^{2}=.06$ (see Figure 3 ).

To test our specific predictions, we probed the interaction by calculating mean paternal investment estimates for women one standard deviation above or below the mean for age-at-menarche (Aiken \& West, 1991). At one standard deviation below the mean for age-at-menarche (i.e., early age-at-menarche), ovulating women expected sexy cads to contribute significantly more paternal investment than did non-ovulating women, $t(170)=2.97, p=$ $.003, \eta^{2}=.05$ (see Figure 3). For women one standard deviation above the mean for age-at-menarche (i.e., late age-at-menarche), there was a marginal effect of fertility. In contrast to the early women, ovulating women who had later ages at menarche perceived sexy cads to be slightly worse fathers, $t(170)=1.94, p=$ $.054, \eta^{2}=.02$ (see Figure 3).

Commitment and stability. We next examined how fertility and age-at-menarche influenced perceptions of commitment and stability for normally cycling (non-pill using) women. A general linear model with Fertility (high vs. low) as a between-subjects factor and Age-at-Menarche as a zero-centered continuous factor

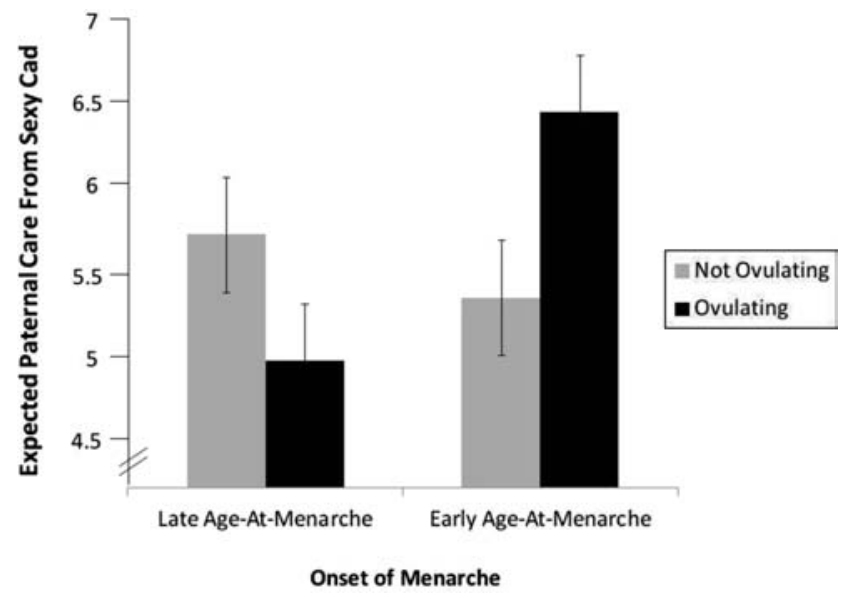

Figure 3. Women's expected paternal investment in a child by a sexy and charismatic cad as a function of fertility status and age-at-menarche (Study 3). Graphed means represent a median split of age-at-menarche. Error bars indicate the standard error of the mean.

revealed a significant interaction between fertility and age-atmenarche, $F(1,171)=9.17, p=.003, \eta_{p}^{2}=.05$ (see Figure 4).

To test our specific predictions, we probed the interaction by calculating mean commitment and stability estimates for women one standard deviation above or below the mean for age-atmenarche. At one standard deviation below the mean (i.e., early age-at-menarche), ovulating women perceived sexy cads as more committed and stable than did non-ovulating women, $t(171)=$ 2.77, $p=.006, \eta^{2}=.04$ (see Figure 4). For women one standard deviation above the mean (i.e., late age-at-menarche), there was no significant effect of fertility ( $p=.16$ ). However, an examination of the means revealed that ovulating women who had later ages at menarche perceived sexy cads to be slightly less committed and stable (see Figure 4).

Perceptions across the cycle. For descriptive purposes, we plotted findings for all women across the full 28-day cycle, including women who were outside the peri-ovulatory and luteal phases of the cycle. Because the paternal investment and commitment/stability findings showed very similar patterns, we first created a composite of all the items $(\alpha=.84)$. We then plotted Loess smoothed curves for perceptions of cads across the cycle for three different segments of women: (1) women not on contraceptives who had earlier ages of menarche, (2) women not on contraceptives who had later ages of menarche, and (3) women on hormonal contraceptives (the pill).

Figure 5A depicts the probability of conception across a normal ovulatory cycle (Wilcox et al., 2001). Conception is highest near the time of ovulation. Figure 5B depicts perceptions of sexy cads for Early Menarche Women who were not on hormonal birth control. The pattern of findings for this group of women shows high resemblance to the probability curve in Figure 5A. For women who were following a faster reproductive strategy (as indexed by earlier age of menarche), perceptions of sexy cads across the ovulatory cycle track conception probability well. Sexy cads are most likely to be seen as investing fathers and committed relationship partners near peak fertility.

Figure 5C depicts the Late Menarche Women who were not on hormonal birth control. Unlike their early menarche counterparts 


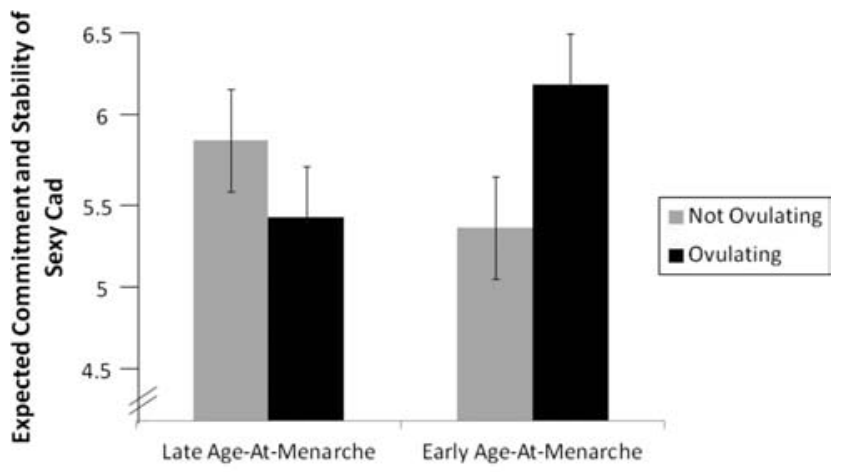

Onset of Menarche

Figure 4. Women's perceptions of the sexy and charismatic cad's commitment and stability as a function of fertility status and age-at-menarche (Study 3). Graphed means represent a median split of age-at-menarche. Error bars indicate the standard error of the mean.

who were following a faster reproductive strategy, slower strategy women (as indexed by later age of menarche) do not show the same effect of fertility on perceptions of sexy cads. If anything, an opposite pattern is indicated: Women who experienced later ages at menarche view sexy cads as slightly worse fathers and less committed partners near ovulation (also see Figures 3 and 4). Finally, Figure 5D depicts the findings for women who were on hormonal contraceptives (the pill). As would be expected, these women do not show any consistent effect across the cycle.

\section{Discussion}

Study 3 conceptually replicates and extends the findings from the first two studies. Drawing from a larger and more diverse sample of women, the Study 3 findings show that ovulation not only leads women to see sexy cads as better fathers, but also as more committed and stable romantic partners. These results suggest that ovulation leads sexy cads to be perceived as both better future fathers and more dependable relationship partners.

Study 3 also shows that this ovulatory perceptual shift effect is driven by a particular group of women-those who are following a faster, short-term reproductive strategy, as indexed by their earlier pubertal timing. Ovulation produces a perceptual shift when evaluating sexy cads only for women who experienced earlier age of menarche, which is a physiological marker of faster reproductive strategies (Flannery et al., 1993; Furstenberg et al., 1989; Luster \& Mittelstaedt, 1993; Udry, 1979). From an evolutionary perspective, women who pursue faster strategies have more to gain and less to lose by being drawn to physically attractive, socially dominant, adventurous, and charismatic men who may also be more likely to cheat on, lie to, and leave them. In contrast, ovulation does not significantly alter perceptions of sexy cads among women who experienced menarche later, which is a marker of slower, long-term reproductive strategies. In fact, women who are following a slower strategy perceive sexy cads as slightly
A

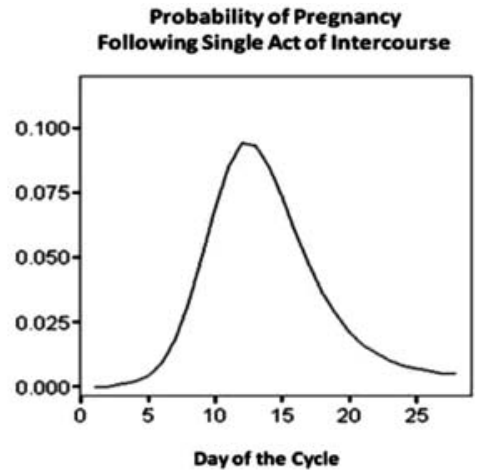

C
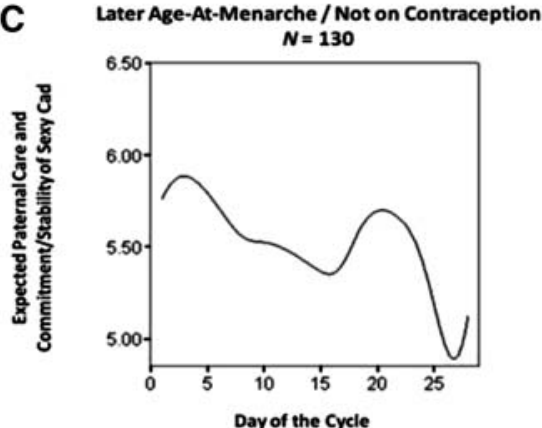

B Earlier Age-At-Menarche / Not on Contraception $N=188$
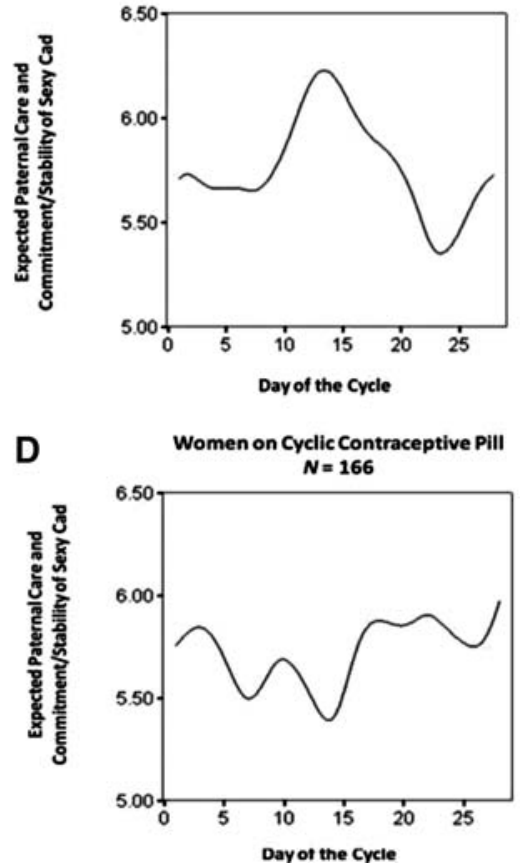

Figure 5. Probability of conception across the cycle (5A) and Loess smoothed curves of perceptions of a sexy cad's paternal investment and commitment during the cycle for three female groups (Study 3): (5B) women not on contraceptives who had earlier ages of menarche, $(5 \mathrm{C})$ women not on contraceptives who had later ages of menarche, and (5D) women on cyclic hormonal contraceptives (the pill). 
worse fathers and less committed relationship partners near ovulation (see Figures 3 and 4).

\section{General Discussion}

Across three studies, we found that ovulation leads women to perceive sexy cads as relatively more investing dads. Ovulating women appear to over-perceive that charismatic and adventurous cads will become more-investing fathers and more committed and stable romantic partners, at least with respect to them. This ovulatory perceptual shift may motivate certain women to believe that it is reasonable to accept romantic offers from men who might be unfaithful and could desert them. When presented with a romantic offer from a sexy cad, the hormonal changes associated with fertility can lead Mr. Wrong to appear like Mr. Right.

Additional evidence revealed the specificity of this ovulatoryinduced perceptual shift, offering insight into the proximate mechanism of this effect. First, the ovulatory perceptual shift effect occurs only when women are evaluating certain types of males. Ovulation changed perceptions of sexy cads, but not perceptions of reliable, nice guys (Studies 1 and 2). Second, the ovulatory perceptual shift effect occurs only for the female observer's offspring. Ovulating women believe that a charismatic and adventurous cad will be a better father if he conceives a child with them, but not with other women (Study 2). This finding supports previous work showing that positive illusions tend to be specific to one's own evaluations of the partner and not outsider evaluations (Murray et al., 2000). Third, the ovulatory perceptual shift effect occurs for only certain male traits. Ovulating women viewed sexy cads as better fathers and more committed romantic partners, but not as more attractive or higher status men (Studies 2 and 3). Finally, the ovulatory perceptual shift effect is driven by a specific subset of women. Ovulation produced a sexy cad perceptual shift for women who were pursuing a faster, short-term reproductive strategy (as indexed by earlier age-at-menarche), but not for women who were following a slower, long-term reproductive strategy.

The pattern of findings remained consistent regardless of whether fertility was assessed via urine tests (Study 1 and Study 2) or via a cycle counting method (Study 3). The pattern also remained similar regardless of whether women rated men based on their photo-profiles (Study 1), biographical written profile (Study 3 ), or videotaped actors who portrayed both the sexy cad and the reliable dad to control for confounds (Study 2). Furthermore, the extent of the sexy cad perceptual shift effect closely tracked the probability of conception across the cycle (Study 3; see Figure 5), providing strong evidence that the effect is driven by hormonal fluctuations associated with fertility.

\section{Proximate and Ultimate Mechanisms}

Our findings are consistent with and build on a wealth of ovulatory research indicating that the primary ultimate (evolutionary) reason women pursue physically attractive, socially dominant, charismatic, and masculine men-who often make unreliable longterm partners-is to obtain genetic benefits (e.g., Haselton \& Gangestad, 2006; Haselton \& Miller, 2006; Gangestad et al., 2004, 2002; Johnston et al., 2001; Penton-Voak et al., 1999; Puts, 2005). The current research focused on proximate mechanisms for this effect. Previous work posits that the proximate mechanism moti- vating women to pursue sexy cads is the desire for short-term sexual relationships (e.g., Gangestad et al., 2007, 2004; Haselton \& Miller, 2006; Penton-Voak et al., 1999; Puts, 2005). We argued, however, that this proximate mechanism for women's motivation to seek sexy cads is incomplete. Building on previous findings, across three studies we document a novel and complementary hormonally driven proximate mechanism why women pursue sexy cads: Ovulating women over-perceive that such men will become investing dads and perhaps even committed long-term partners (see Buss \& Schmitt, 1993).

An important question to address in future research is the precise psychological mechanism that underlies this hormonally induced perceptual bias. While previous research has found that women are more attracted to the characteristics and features of sexy cads near ovulation (e.g., Gangestad et al., 2004, 2002 Penton-Voak et al., 1999), little is known about the cognitions that accompany the desire to pursue these men as sexual partners. One possibility is that the perceptual shift in partner investment attributes at ovulation is a dissonance-reducing mechanism. Because the hormones associated with ovulation increase women's sexual desire (Bullivant et al., 2004), and this desire is directed more strongly toward sexy cads (Gangestad et al., 2004), the shift in perception regarding the parenting and partner attributes of sexy cads could be a psychological mechanism that reduces the dissonance created from the hormonally induced desire to pursue men who are unlikely to become committed partners. Otherwise, a preoccupation with the relationship costs associated with sexy cads could undermine the hormonally driven motivation to pursue them as sexual partners (Kelley, 1979; Van Lange et al., 1997).

A significant body of research has shown that the goals, drives, and interests of two people who enter a romantic partnership are not always aligned (e.g., Kelley, 1979; Lykken \& Tellegen, 1993; Van Lange et al., 1997). Thus, in order to pursue, attain, and maintain a romantic union, people often have to convince themselves that the other person is the "right" partner for them (Holmes \& Rempel, 1989; Murray, 1999). If ovulatory hormones drive women to pursue sexy cads, women may experience a psychological need to justify this committed action (Festinger, 1957; Taylor $\&$ Gollwitzer, 1995). Thus, the perceptual shift in partner attributes at ovulation may reduce the cognitive dissonance associated with pursuing sexy cads, providing the extra "push" that many women may need to engage in sex with men high in genetic quality (and who typically do not possess good long-term partner characteristics). Therefore, the belief that "I can be the one who finally reins him in" could be the cognitive distortion that facilitates women's ability to maximize reproductive outcomes when their probability of conception is highest.

\section{Implications, Limitations, and Future Directions}

When it comes to romantic partners, women ideally want it all (Fletcher et al., 1999; Li et al., 2002). Previous research outlines four sets of characteristics that are highly valued by women in a long-term mate (Buss \& Shackelford, 2008; see also Simpson \& Gangestad, 1992): (1) indictors of genetic fitness (e.g., masculinity and social dominance), (2) ability to acquire resources (e.g., status, ambition), (3) good parenting skills, and (4) good relationship partner indicators (e.g., stability). 
Previous ovulation research has focused primarily on the first category, examining how ovulation influences women's desire for indicators of genetic fitness. This work has confirmed that ovulating women desire genetic fitness indicators such as facial and vocal masculinity, symmetry, intelligence, intrasexual competitiveness, and social dominance when evaluating men as short-term sexual partners (Haselton \& Gangestad, 2006; Haselton \& Miller, 2006; Gangestad et al., 2004, 2002; Johnston et al., 2001; PentonVoak \& Perrett, 2000; Penton-Voak et al., 1999; Puts, 2005). However, previous ovulation research has paid less attention to the other sets of characteristics women desire in mates.

Extending the literature on ovulatory effects, we examined how ovulation influences women's perceptions of men's parenting ability and long-term relationship partner potential. In three studies, we consistently find that some ovulating women, at the proximate level, come to view sexy cads as better parents and better longterm relationship partners compared to non-ovulating women. While ovulating women come to perceive sexy cads as long-term partner material, we contend that, at the non-conscious ultimate level, pursuing sexy cads is primarily related to following a shortterm strategy, which is associated with extracting genetic benefits. This is because, although women proximally desire long-term relations with genetically fit men, such men are not actually reliable, investing long-term partners. Thus, when taken together with the substantial amount of research associating ovulation with obtaining short-term genetic benefits, our findings suggests that the ovulatory shift in perceiving sexy cads as good dads is ultimately more of a short-term sexual strategy geared toward securing genetic benefits with an occasional long-term payoff.

The current research has some limitations that open the door for future research on the proximate mechanisms that motivate ovulating women to pursue sexy cads. For example, because we did not measure actual short-term versus long-term mating outcomes, future research is needed to accurately determine whether the perceptual bias is indeed more of a short-term sexual strategy. We also measured only a few traits and characteristics relevant to mating. Future research could examine whether other long-term relationship perceptions or feelings such as love, passion, and attachment toward sexy cads might also shift near ovulation (see Brumbaugh \& Fraley, 2006; Tancredy \& Fraley, 2006). Further, while many women are not likely to be consciously aware that they perceive sexy cads as better future fathers and romantic partners at ovulation, the question of how conscious these effects are remains unanswered. It is also unclear whether women whose current romantic partners are particularly attractive would experience the same shifts in perceptions of sexy cads. Previous research suggests that women who are highly satisfied with their current romantic partners might not view sexy cads as better fathers near ovulation (Haselton \& Gangestad, 2006; Pillsworth \& Haselton, 2006). Future research should also assess attributes of a woman's partner (e.g., his physical attractiveness, status, symmetry) and whether these attributes attenuate the ovulatory perceptual bias when she evaluates sexy cads. Finally, it is important to remember that the ovulatory shift effect on the perception of sexy and charismatic men was driven by a specific group of women in Study 3-those who were on a fast reproductive path as indexed by their early age-at-menarche.

\section{Conclusion}

Although it can be risky for women to pursue genetically fit mates who may eventually abandon them, genetic benefits may have offset potential costs in specific situations during evolutionary history. If so, the ovulatory-induced perceptual shift identified in the current research could be construed as an "adaptive perceptual shift" consistent with error management theory (Haselton \& Buss, 2000; Haselton \& Nettle, 2006). This perceptual shift would have persuaded some women to take mating risks by facilitating greater sexual receptivity to genetically fit men. Missing a mating opportunity with such men would have been more costly for these women at high fertility. After all, you never know; you could be "the one."

\section{References}

Aiken, L. S., \& West, S. G. (1991). Multiple regression: Testing and interpreting interactions. Thousand Oaks, CA: Sage.

Belsky, J., Steinberg, L., \& Draper, P. (1991). Childhood experience, interpersonal development, and reproductive strategy: An evolutionary theory of socialization. Child Development, 62, 647-670. doi:10.2307/1131166

Brumbaugh, C. C., \& Fraley, R. C. (2006). The evolution of attachment in romantic relationships. In M. Mikulincer \& G. Goodman (Eds.), The dynamics of romantic love: Attachment, caregiving, and sex (pp. 71101). New York, NY: Guilford Press.

Bullivant, S. B., Sellergren, S. A., Stern, K., Spencer, N. A., Jacob, S., Mennella, J. A., \& McClintock, M. K. (2004). Women's sexual experience during the menstrual cycle: Identification of the sexual phase by noninvasive measurement of luteinizing hormone. Journal of Sex Research, 41, 82-93. doi:10.1080/00224490409552216

Buss, D. M. (1991). Mate selection for good parenting skills. Behavioral and Brain Sciences, 14, 520-521. doi:10.1017/S0140525X00071107

Buss, D. M. (2003). The evolution of desire: Strategies of human mating. New York, NY: Basic Books.

Buss, D. M., Abbott, M., Angleitner, A., Asherian, A., Biaggio, A., Blanco-Villasenor, A., . . Y Yang, K.-S. (1990). International preferences in selecting mates: A study of 37 societies. Journal of Cross-Cultural Psychology, 21, 5-47. doi:10.1177/0022022190211001

Buss, D. M., \& Schmitt, D. P. (1993). Sexual strategies theory: A contextual evolutionary analysis of human mating. Psychological Review, 100, 204-232. doi:10.1037/0033-295X.100.2.204

Buss, D. M., \& Shackelford, T. K. (2008). Attractive women want it all: Good genes, economic investment, parenting proclivities, and emotional commitment. Evolutionary Psychology, 6, 134-146.

Campbell, W. K., Foster, C. A., \& Finkel, E. J. (2002). Does self-love lead to love for others? A story of narcissistic game playing. Journal of Personality and Social Psychology, 83, 340-354. doi:10.1037/0022-3514.83.2.340

Chisholm, J. S. (1999). Attachment and time preference: Relations between early stress and sexual behavior in a sample of American university women. Human Nature, 10, 51-83. doi:10.1007/s12110-999-1001-1

Clark, R. D., III, \& Hatfield, E. (1989). Gender differences in receptivity to sexual offers. Journal of Psychology \& Human Sexuality, 2, 39-55. doi:10.1300/J056v02n01_04

Confer, J. C., Easton, J. A., Fleischman, D. S., Goetz, C. D., Lewis, D. M., Perilloux, C., \& Buss, D. M. (2010). Evolutionary psychology: Controversies, questions, prospects, and limitations. American Psychologist, 65, 110-126.

DeBruine, L. M., Jones, B. C., Frederick, D. A., Haselton, M. G., PentonVoak, I. S., \& Perrett, D. I. (2010). Evidence for menstrual cycle shifts in women's preferences for masculinity: A response to Harris (in press) "Menstrual cycle and facial preferences reconsidered." Evolutionary Psychology, 8, 768-775.

DeBruine, L. M., Jones, B. C., \& Perrett, D. I. (2005). Women's attractiveness 
judgments of self-resembling faces change across the menstrual cycle. Hormones and Behavior, 47, 379-383. doi:10.1016/j.yhbeh.2004.11.006

Draper, P., \& Belsky, J. (1990). Personality development in evolutionary perspective. Journal of Personality, 58, 141-161. doi:10.1111/j.14676494.1990.tb00911.x

Draper, P., \& Harpending, H. (1982). Father absence and reproductive strategy: An evolutionary perspective. Journal of Anthropological Research, 38, 255-273.

Durante, K. M., Griskevicius, V., Hill, S. E., Perilloux, C., \& Li, N. P. (2011). Ovulation, female competition, and product choice: Hormonal influences on consumer behavior. Journal of Consumer Research, 37(5). doi: $10.1086 / 656575$

Durante, K. M., Li, N. P., \& Haselton, M. G. (2008). Changes in women's choice of dress across the ovulatory cycle: Naturalistic and laboratory task-based evidence. Personality and Social Psychology Bulletin, 34, 1451-1460. doi:10.1177/0146167208323103

Durocher, L., \& Linn, E. (1975). Nice guys finish last. New York, NY: Simon and Schuster

Ellis, B. J. (2004). Timing of pubertal maturation in girls: An integrated life history approach. Psychological Bulletin, 130, 920-958. doi:10.1037/ 0033-2909.130.6.920

Ellis, B. J. (2005). Individual differences in pubertal timing: An evolutionary-developmental approach. In B. J. Ellis \& D. F. Bjorklund (Eds.), Origins of the social mind: Evolutionary psychology and child development (pp. 164-188). New York, NY: Guilford Press.

Feinberg, D. R., Jones, B. C., Law Smith, M. J., Moore, F. R., DeBruine, L. M., Cornwell, R. E., ... Perrett, D. I. (2006). Menstrual cycle, trait estrogen level, and masculinity preferences in the human voice. Hormones and Behavior, 49, 215-222. doi:10.1016/j.yhbeh.2005.07.004

Festinger, L. (1957). A theory of cognitive dissonance. Stanford, CA: Stanford University Press.

Flannery, D. J., Rowe, D. C., \& Gulley, B. L. (1993). Impact of pubertal status, timing, and age on adolescent sexual experience and delinquency. Journal of Adolescent Research, 8, 21-40. doi:10.1177/074355489381003

Fleischman, D. S., Navarrete, C. D., \& Fessler, D. M. T. (2010). Oral contraceptives suppress ovarian hormone production. Psychological Science, 21, 750-752. doi:10.1177/0956797610368062

Fletcher, G. J. O., Simpson, J. A., Thomas, G., \& Giles, L. (1999). Ideals in intimate relationships. Journal of Personality and Social Psychology, 76, 72-89. doi:10.1037/0022-3514.76.1.72

Frederick, D. A., \& Haselton, M. G. (2007). Why is muscularity sexy? Tests of the fitness indicator hypothesis. Personality and Social Psychology Bulletin, 33, 1167-1183. doi:10.1177/0146167207303022

Furstenberg, F. F., Brooks-Gunn, J., \& Chase-Lansdale, L. (1989). Teenaged pregnancy and childbearing. American Psychologist, 44, 313-320. doi:10.1037/0003-066X.44.2.313

Gangestad, S. W., Garver-Apgar, C. E., Simpson, J. A., \& Cousins, A. J. (2007). Changes in women's mate preferences across the ovulatory cycle. Journal of Personality and Social Psychology, 92, 151-163. doi:10.1037/0022-3514.92.1.151

Gangestad, S. W., \& Simpson, J. A. (2000). The evolution of human mating: Trade-offs and strategic pluralism. Behavioral and Brain Sciences, 23, 573-587. doi:10.1017/S0140525X0000337X

Gangestad, S. W., Simpson, J. A., Cousins, A. J., Garver-Apgar, C. E., \& Christensen, P. N. (2004). Women's preferences for male behavioral displays across the menstrual cycle. Psychological Science, 15, 203207. doi:10.1111/j.0956-7976.2004.01503010.x

Gangestad, S. W., \& Thornhill, R. (1997). Human sexual selection and developmental stability. In J. A. Simpson \& D. T. Kenrick (Eds.), Evolutionary social psychology (pp. 169-196). Mahwah, N J: Erlbaum.

Gangestad, S. W., \& Thornhill, R. (1998). Menstrual cycle variation in women's preferences for the scent of symmetrical men. Proceedings of the Royal Society B: Biological Sciences, 265, 927-933. doi:10.1098/ rspb.1998.0380
Gangestad, S. W., \& Thornhill, R. (2008). Human oestrus. Proceedings of the Royal Society B: Biological Sciences, 275, 991-1000. doi:10.1098/ rspb.2007.1425

Gangestad, S. W., Thornhill, R., \& Garver, C. E. (2002). Changes in women's sexual interests and their partner's mate-retention tactics across the menstrual cycle: Evidence for shifting conflicts of interest Proceedings of the Royal Society B: Biological Sciences, 269, 975-982. doi:10.1098/rspb.2001.1952

Gangestad, S. W., Thornhill, R., \& Garver-Apgar, C. E. (2005). Women's sexual interest across the ovulatory cycle depending on primary partner fluctuating asymmetry. Proceedings of the Royal Society B: Biological Sciences, 272, 2023-2027. doi:10.1098/rspb.2005.3112

Gangestad, S. W., Thornhill, R., \& Garver-Apgar, C. E. (2010). Fertility in the cycle predicts women's interest in sexual opportunism. Evolution and Human Behavior, 31, 400-411. doi:10.1016/j.evolhumbehav.2010.05.003

Garver-Apgar, C. E., Gangestad, S. W., Thornhill, R., Miller, R. D., \& Olp, J. J. (2006). Major histocompatibility complex alleles, sexual responsivity, and unfaithfulness in romantic couples. Psychological Science, 17, 830-835. doi:10.1111/j.1467-9280.2006.01789.x

Gottlieb, L. (2010). Marry him: The case for settling for Mr. Good Enough. New York, NY: Dutton.

Griskevicius, V., Cialdini, R. B., \& Kenrick, D. T. (2006). Peacocks, Picasso, and parental investment: The effects of romantic motives on creativity. Journal of Personality and Social Psychology, 91, 63-76. doi:10.1037/0022-3514.91.1.63

Griskevicius, V., Tybur, J. M., Sundie, J. M., Cialdini, R. B., Miller, G. F., \& Kenrick, D. T. (2007). Blatant benevolence and conspicuous consumption: When romantic motives elicit strategic costly signals. Journal of Personality and Social Psychology, 93, 85-102. doi:10.1037/0022-3514.93.1.85

Haselton, M. G., \& Buss, D. M. (2000). Error management theory: A new perspective on biases in cross-sex mind reading. Journal of Personality and Social Psychology, 78, 81-91. doi:10.1037/0022-3514.78.1.81

Haselton, M. G., \& Gangestad, S. W. (2006). Conditional expression of women's desires and men's mate guarding across the ovulatory cycle. Hormones and Behavior, 49, 509-518. doi:10.1016/j.yhbeh.2005.10.006

Haselton, M. G., \& Miller, G. F. (2006). Women's fertility across the cycle increases the short-term attractiveness of creative intelligence compared to wealth. Human Nature, 17, 50-73. doi:10.1007/s12110-006-1020-0

Haselton, M. G., \& Nettle, D. (2006). The paranoid optimist: An integrative evolutionary model of cognitive biases. Personality and Social Psychology Review, 10, 47-66. doi:10.1207/s15327957pspr1001_3

Holmes, J. G., \& Rempel, J. K. (1989). Trust in close relationships. In C. Hendrick (Ed.), Close relationships (pp. 187-220). Thousand Oaks, CA: Sage.

Hughes, S. M., \& Gallup, G. G., Jr. (2003). Sex differences in morphological predictors of sexual behavior: Shoulder to hip and waist to hip ratios. Evolution and Human Behavior, 24, 173-178. doi:10.1016/ S1090-5138(02)00149-6

Jobling, I. (2002). Byron as cad. Philosophy and Literature, 26, 296-311. doi: $10.1353 / \mathrm{phl} .2003 .0010$

Johnston, V. S., Hagel, R., Franklin, M., Fink, B., \& Grammer, K. (2001). Male facial attractiveness: Evidence for a hormone-mediated adaptive design. Evolution and Human Behavior, 22, 251-267. doi:10.1016/ S1090-5138(01)00066-6

Jonason, P. K., Li, N. P., Webster, G. D., \& Schmitt, D. P. (2009). The dark triad: Facilitating a short-term mating strategy in men. European Journal of Personality, 23, 5-18. doi:10.1002/per.698

Jonason, P. K., \& Tost, J. (2010). I just cannot control myself: The dark triad and self-control. Personality and Individual Differences, 49, 611615. doi:10.1016/j.paid.2010.05.031

Jonason, P. K., \& Webster, G. D. (2010). The dirty dozen: A concise measure of the dark triad. Psychological Assessment, 22, 420-432. doi: $10.1037 / \mathrm{a} 0019265$

Jones, B. C., Boothroyd, L. G., Feinberg, D. R., \& DeBruine, L. M. (2010). Age at menarche predicts individual differences in women's preferences 
for masculinized male voices in adulthood. Personality and Individual Differences, 48, 860-863. doi:10.1016/j.paid.2010.02.007

Jones, B. C., DeBruine, L. M., Perrett, D. I., Little, A. C., Feinberg, D. R., \& Law Smith, M. J. (2008). Effects of menstrual cycle phase on face preferences. Archives of Sexual Behavior, 37, 78-84. doi:10.1007/ s10508-007-9268-y

Kelley, H. H. (1979). Personal relationships: Their structures and processes. Hillsdale, NJ: Erlbaum.

Kenrick, D. T., Griskevicius, V., Neuberg, S. L., \& Schaller, M. (2010). Renovating the pyramid of needs: Contemporary extensions built upon ancient foundations. Perspectives on Psychological Science, 5, 292-314. doi: $10.1177 / 1745691610369469$

Kim, K., \& Smith, P. K. (1998). Retrospective survey of parental marital relations and child reproductive development. International Journal of Behavioral Development, 22, 729-751. doi:10.1080/016502598384144

Kim, K., Smith, P. K., \& Palermiti, A. (1997). Conflict in childhood and reproductive development. Evolution and Human Behavior, 18, 109142. doi:10.1016/S1090-5138(96)00114-6

Kruger, D., Fisher, M., \& Jobling, I. (2003). Proper and dark heroes as dads and cads. Human Nature, 14, 305-317. doi:10.1007/s12110-003-1008-y

Lancaster, J. B., \& Kaplan, H. (1992). Human mating and family formation strategies: The effects of variability among males in quality and the allocation of mating effort and parental investment. In T. Nishida, W. C. McGrew, P. Marler, M. Pickford, \& F. B. deWaal (Eds.), Topics in primatology (pp. 21-33). Tokyo, Japan: University of Tokyo Press.

Li, N. P., Bailey, J. M., Kenrick, D. T., \& Linsenmeier, J. A. W. (2002). The necessities and luxuries of mate preferences: Testing the trade-offs. Journal of Personality and Social Psychology, 82, 947-955. doi: 10.1037/0022-3514.82.6.947

Li, N. P., \& Kenrick, D. T. (2006). Sex similarities and differences in preferences for short-term mates: What, whether, and why. Journal of Personality and Social Psychology, 90, 468-489. doi:10.1037/00223514.90.3.468

Little, A. C., Jones, B. C., \& DeBruine, L. M. (2008). Preferences for variation in masculinity in real male faces change across the menstrual cycle. Personality and Individual Differences, 45, 478-482. doi: 10.1016/j.paid.2008.05.024

Louis, R., \& Copeland, D. (2007). How to be the bad boy women love: Getting hot women to pursue you by being a "hard to get" man. Madison, WI: Mastery Technologies.

Lukaszewski, A. W., \& Roney, J. R. (2009). Estimated hormones predict women's mate preferences for dominant personality traits. Personality and Individual Differences, 47, 191-196. doi:10.1016/j.paid.2009.02.019

Luster, T., \& Mittelstaedt, M. (1993). Adolescent mothers. In T. Luster \& L. Okagaki (Eds.), Parenting: An ecological perspective (pp. 69-99). Hillsdale, NJ: Erlbaum.

Lykken, D. T., \& Tellegen, A. (1993). Is human mating adventitious or the result of lawful choice? A twin study of mate selection. Journal of Personality and Social Psychology, 65, 56-68. doi:10.1037/0022-3514.65.1.56

Mayr, E. (1988). Toward a new philosophy of biology: Observations of an evolutionist. Cambridge, MA: Harvard University Press.

McDaniel, A. K. (2005). Young women's dating behavior: Why/why not date a nice guy? Sex Roles, 53, 347-359. doi:10.1007/s11199-005-6758-Z

Møller, A. P., \& Thornhill, R. (1998). Male parental care, differential parental investment by females and sexual selection. Animal Behaviour, 55, 1507-1515. doi:10.1006/anbe.1998.0731

Murray, S. L. (1999). The quest for conviction: Motivated cognition in romantic relationships. Psychological Inquiry, 10, 23-34. doi:10.1207/ s15327965pli1001_3

Murray, S. L., Holmes, J. G., Dolderman, D., \& Griffin, D. W. (2000). What the motivated mind sees: Comparing friends' perspectives to married partners' views of each other. Journal of Experimental Social Psychology, 36, 600-620. doi:10.1006/jesp.1999.1417

Murray, S. L., Holmes, J. G., \& Griffin, D. W. (1996a). The benefits of positive illusions: Idealization and the construction of satisfaction in close relationships. Journal of Personality and Social Psychology, 70, 79-98. doi:10.1037/0022-3514.70.1.79

Murray, S. L., Holmes, J. G., \& Griffin, D. W. (1996b). The self-fulfilling nature of positive illusions in romantic relationships: Love is not blind, but prescient. Journal of Personality and Social Psychology, 71, 11551180. doi:10.1037/0022-3514.71.6.1155

Paulhus, D. L. (2001). Normal narcissism: Two minimalist accounts. Psychological Inquiry, 12, 228-230.

Paulhus, D. L., \& Williams, K. M. (2002). The dark triad of personality: Narcissism, Machiavellianism, and psychopathy. Journal of Research in Personality, 36, 556-563. doi:10.1016/S0092-6566(02)00505-6

Penton-Voak, I. S., \& Perrett, D. I. (2000). Female preference for male faces changes cyclically-Further evidence. Evolution and Human Behavior, 21, 39-48. doi:10.1016/S1090-5138(99)00033-1

Penton-Voak, I. S., Perrett, D. I., Castles, D. L., Kobayashi, T., Burt, D. M., Murray, L. K., \& Minamisawa, R. (1999, June 24). Menstrual cycle alters face preference. Nature, 399, 741-742. doi:10.1038/21557

Pillsworth, E. G., \& Haselton, M. G. (2006). Male sexual attractiveness predicts differential ovulatory shifts in female extra-pair attraction and male mate retention. Evolution and Human Behavior, 27, 247-258. doi:10.1016/j.evolhumbehav.2005.10.002

Pillsworth, E. G., Haselton, M. G., \& Buss, D. M. (2004). Ovulatory shifts in female sexual desire. Journal of Sex Research, 41, 55-65. doi: 10.1080/00224490409552213

Puts, D. A. (2005). Mating context and menstrual phase affect female preferences for male voice pitch. Evolution and Human Behavior, 26, 388-397. doi:10.1016/j.evolhumbehav.2005.03.001

Rhodes, G., Simmons, L. W., \& Peters, M. (2005). Attractiveness and sexual behavior: Does attractiveness enhance mating success? Evolution and Human Behavior, 26, 186-201. doi:10.1016/j.evolhumbehav.2004.08.014

Schmitt, D. P. (2005). Sociosexuality from Argentina to Zimbabwe: A 48-nation study of sex, culture, and strategies of human mating. Behavioral and Brain Sciences, 28, 247-275. doi:10.1017/S0140525X05000051

Simpson, J. A., \& Gangestad, S. (1992). Sociosexuality and romantic partner choice. Journal of Personality, 60, 31-51. doi:10.1111/j.14676494.1992.tb00264.x

Simpson, J. A., Gangestad, S. W., Christensen, P. N., \& Leck, K. (1999). Fluctuating asymmetry, sociosexuality, and intrasexual competitive tactics. Journal of Personality and Social Psychology, 76, 159-172. doi: 10.1037/0022-3514.76.1.159

Smith, F. G., Jones, B. C., Little, A. C., DeBruine, L. M., Welling, L. L. M., Vukovic, J., \& Conway, C. A. (2009). Hormonal contraceptive use and perceptions of trust modulate the effect of relationship context on women's preferences for sexual dimorphism in male face shape. Journal of Evolutionary Psychology, 7, 195-210. doi:10.1556/JEP.7.2009.3.1

Sundie, J. M., Kenrick, D. T., Griskevicius, V., Tybur, J. M., Vohs, K. D., \& Beal, D. J. (2011). Peacocks, Porsches, and Thorstein Veblen: Conspicuous consumption as a sexual signaling system. Journal of Personality and Social Psychology, 100, 664-680. doi:10.1037/a0021669

Tancredy, C. M., \& Fraley, R. C. (2006). The nature of adult twin relationships: An attachment-theoretical perspective. Journal of Personality and Social Psychology, 90, 78-93. doi:10.1037/0022-3514.90.1.78

Taylor, S. E., \& Gollwitzer, P. M. (1995). Effects of mindset on positive illusions. Journal of Personality and Social Psychology, 69, 213-226. doi:10.1037/0022-3514.69.2.213

Thornhill, R., \& Gangestad, S. W. (1994). Fluctuating asymmetry correlates with lifetime sex partner numbers and age at first sex in Homo sapiens. Psychological Science, 5, 297-302. doi:10.1111/j.14679280.1994.tb00629.x

Thornhill, R., \& Gangestad, S. W. (2003). Do women have evolved adaptation for extra-pair copulation? In K. Grammer \& E. Voland (Eds.), Evolutionary aesthetics (pp. 341-368). Berlin, Germany: Springer-Verlag.

Thornhill, R., \& Gangestad, S. W. (2006). Facial sexual dimorphism, develop- 
mental stability, and susceptibility to disease in men and women. Evolution and Human Behavior, 27, 131-144. doi:10.1016/j.evolhumbehav.2005.06.001

Thornhill, R., \& Gangestad, S. W. (2008). The evolutionary biology of human female sexuality. New York, NY: Oxford University Press.

Thornhill, R., Gangestad, S. W., Miller, R., Scheyd, G., Knight, J., \& Franklin, M. M. (2003). MHC, symmetry, and body scent attractiveness in men and women. Behavioral Ecology, 14, 668-678. doi:10.1093/ beheco/arg043

Udry, J. R. (1979). Age at menarche, at first intercourse, and at first pregnancy. Journal of Biosocial Science, 11, 433-441. doi:10.1017/ S0021932000012517

Van Lange, P. A. M., Rusbult, C. E., Drigotas, S. M., Arriaga, X. B., Witcher, B. S., \& Cox, C. L. (1997). Willingness to sacrifice in close relationships. Journal of Personality and Social Psychology, 72, 13731395. doi:10.1037/0022-3514.72.6.1373

Waynforth, D. (2001). Mate choice trade-offs and women's preferences for physically attractive men. Human Nature, 12, 207-219. doi:10.1007/ s12110-001-1007-9

Waynforth, D., Delwadia, S., \& Camm, M. (2005). The influence of women's mating strategies on preference for masculine facial architecture. Evolution and Human Behavior, 26, 409-416. doi:10.1016/ j.evolhumbehav.2005.03.003

Wilcox, A. J., Dunson, D. B., Weinberg, C. R., Trussell, J., \& Baird, D. D. (2001). Likelihood of conception with a single act of intercourse: Providing benchmark rates for assessment of post-coital contraceptives. Contraception, 63, 211-215.

\section{Appendix}

\section{Example of the Scripts for the "Reliable Dad" and the "Sexy Cad" From Study 2}

\section{Good Dad Script}

To portray the "reliable dad," the actors were told to dress casual but not overly fashionable. They were instructed to look away from the camera and not maintain direct eye contact for long periods of time. They were also told to fidget and portray the man as somewhat awkward and not overly confident.

\section{Good dad introduction.}

I don't really know what to say. I'm bad at talking about myself and I'm even worse at talking to cameras. So if this is all wrong, just tell me and I'll start over, though I have no idea what else I'd say besides this, so I kind of hope it's okay.

Basically I'm just a normal guy, or at least I think I'm a normal guy. Or I'm normal enough, I guess. I deliver pizzas for this really popular place in Dinkytown at night and am trying to finish up my English major. I've never been good at the dating thing; I'm really bad at being "cool," and I'm not very smooth or sophisticated. I don't drive an expensive car or go to fancy restaurants or travel around Europe or anything like that. Like I said, I'm just a pretty normal guy. I think I'm a nice guy, too, and I'm looking for a nice woman. I guess together we'll be two nice people, or something like that. I'm not looking for a fling or anything like that, I'd just like to meet someone I have some connection with, someone who's serious about making a life together. I'd like to get married and have a family and all that regular stuff, and I'm looking for someone who feels the same way. So I guess if that sounds good to you, then maybe we can meet and see how it goes, or something like that. And if not, well, I guess just thanks for your time. I'm not sure how to end this. I think I already messed this thing up pretty bad, so I guess I'll just wrap it up here.

SO now I'm supposed to find out about you. I'm going to ask you some questions ... I hope I don't screw this up too.

Uh, nice to meet you, bye.

\section{Sexy Cad Script}

To portray the "sexy cad," the actors were told to dress in a casual but fashionable way. They were instructed to look directly at the camera and maintain eye contact. They were also told to lean forward and exude confidence.

\section{Sexy cad introduction.}

Well, this is a nice change of pace! Usually I do studies where you have to figure out which button to push to get a food pellet and if you push the wrong button, you get an electric shock. But this one is REALLY good because I get to meet and talk with you.

So basically I'm supposed to tell you why you should want to date me. But instead, I'm going to tell you why you should NOT date me. Then, when I'm done, we can talk and really get to know each other better. You should NOT date me if you want a guy who will always be on time, or someone who always remembers every single special event like 2 month anniversaries. You shouldn't date me if you want a guy who can't wait to spend an entire weekend with your high school friends or who understands why you keep so many pillows on your bed. You shouldn't date me if you want a guy who will read you poetry. I don't know many women who want that, but if you do, you probably shouldn't date me. You shouldn't date me if you want someone to watch chick flicks with, or if you hate sports but pretend to love sports because you think that I want to be with someone who loves sports. Really, it's totally okay if you hate sports. I'll just watch sports while you're watching Sex in the City and we'll hang afterwards. You shouldn't date me if you watch absolutely everything you eat and can't appreciate the beauty of a 3 a.m. ice cream excursion or pancakes drowning in butter and syrup, preferably at the end of a late night. And most importantly, you absolutely should NOT date me if you DON'T want to be swept off your feet and have a romance so intense that you'll question everything you ever knew and possibly begin writing with your left hand, or your right one if you're a lefty.

Of course, that's just a theory but, hey, hope springs eternal. But something tells me there are probably a lot of good reasons why you SHOULD date me.

So now I want to find out why I should think about dating you. I'm going to ask you a few questions.

Received May 12, 2011

Revision received March 26, 2012

Accepted March 27, 2012 